\title{
Discent perspectives on the teaching and learning process in a technology course in legal services in distance education modality
}

\author{
Perspectivas de discentes sobre o processo de ensino e aprendizagem \\ em um curso de tecnologia em serviços jurídicos na modalidade \\ educação a distância
}

\section{Perspectivas discentes sobre el proceso de enseñanza y aprendizaje en un curso de tecnología en servicios jurídicos en modalidad educativa a distancia}

\author{
Priscila Santana Vieira1 ${ }^{\text {iD }}$, Bernadete Lema Mazzafera² ${ }^{\text {iD, }}$ \\ ${ }^{1}$ Centro Universitário Filadélfia, Londrina, Paraná, Brasil. \\ 2 Universidade Pitágoras Unopar, Londrina, Paraná, Brasil. \\ Autor correspondente: \\ Bernadete Lema Mazzafera \\ Email: bernalema@gmail.com \\ Como citar: Vieira, P. S., \& Mazzafera, B. L. (2021). Discent perspectives on the teaching and learning process in a \\ technology course in legal services in distance education modality. Revista Tempos e Espaços em Educação, 14(33), \\ e16017. http://dx.doi.org/10.20952/revtee.v14i33.16017
}

\begin{abstract}
The general objective of the study was to describe and analyze students' perspectives on the teaching and learning process in a technology course in legal services in distance education. The study also aimed to identify the profile of the student in the Legal Services course; describe the mastery of digital information and communication technologies by the students of the course; describe the teaching and learning process in the analyzed course; and to analyze the learning difficulties described by the students. Descriptive research with a quantitative and qualitative approach to data analysis was carried out with students from the second, third and fourth semesters of the technology course in Legal Services at a distance from a private university center in northern Paraná. The results obtained indicate that the greatest difficulties that students encounter in this context are of a personal nature. Within this category, academic difficulties predominate, followed by socioeconomic and structural difficulties that obtained the same percentage and difficulties in motivation. Despite indicating that the greatest learning difficulty is of a personal nature, when asked what could make them learn better, the majority indicated changes in instructional design. Keywords: Adult teaching and learning. Difficulties. Distance education. Legal education.
\end{abstract}




\section{RESUMO}

O objetivo geral do estudo foi descrever e analisar perspectivas de discentes sobre o processo de ensino e aprendizagem em um curso de tecnologia em serviços jurídicos na modalidade EaD. $O$ estudo objetivou ainda, identificar o perfil do aluno do curso de Serviços Jurídicos; descrever o domínio das tecnologias digitais de informação e comunicação (TDIC) pelos alunos do curso; descrever o processo de ensino e aprendizagem no curso analisado; e analisar as dificuldades de aprendizagem descritas pelos alunos. A pesquisa descritiva com abordagem quantitativa e qualitativa na análise dos dados foi desenvolvida com alunos do segundo, terceiro e quarto semestre do curso superior de tecnologia em Serviços Jurídicos a distância de um centro universitário particular no norte do Paraná. Os resultados obtidos indicam que as maiores dificuldades que os alunos que encontram nesse contexto são de ordem pessoal. Dentro dessa categoria predominam as dificuldades acadêmicas, seguidas de dificuldades de ordem socioeconômica e estruturais que obtiveram a mesma porcentagem e dificuldades de motivação. Apesar de indicarem que a maior dificuldade de aprendizagem é de cunho pessoal, quando questionados sobre o que poderia fazê-los aprender melhor, a maioria indicou alterações no design instrucional.

Palavras-chave: Dificuldades. Educação a distância. Ensino e aprendizagem de adultos. Ensino jurídico.

\section{RESUMEN}

El objetivo general del estudio fue describir y analizar las perspectivas de los estudiantes sobre el proceso de enseñanza y aprendizaje en un curso de tecnología en servicios legales en educación a distancia. El estudio también tuvo como objetivo identificar el perfil del estudiante en el curso de Servicios Jurídicos; describir el dominio de las tecnologías de la información y la comunicación digitales por parte de los estudiantes del curso; describir el proceso de enseñanza y aprendizaje en el curso analizado; y analizar las dificultades de aprendizaje descritas por los estudiantes. Se realizó una investigación descriptiva con un enfoque cuantitativo y cualitativo de análisis de datos con estudiantes del segundo, tercer y cuarto semestre de la carrera de tecnología en Servicios Legales a distancia de un centro universitario privado en el norte de Paraná. Los resultados obtenidos indican que las mayores dificultades que encuentran los estudiantes en este contexto son de carácter personal. Dentro de esta categoría predominan las dificultades académicas, seguidas de las socioeconómicas y estructurales que obtienen el mismo porcentaje y las dificultades de motivación. A pesar de indicar que la mayor dificultad de aprendizaje es de naturaleza personal, cuando se les preguntó qué podría hacerlos aprender mejor, la mayoría indicó cambios en el diseño instruccional. Palabras clave: Dificultades. Educación a distancia. Educación jurídica. Enseñanza y aprendizaje de adultos.

\section{INTRODUÇÃO}

As graduações tecnológicas, como uma formação em nível superior, têm sua origem e composição na estrutura do ensino profissionalizante brasileiro, da mesma forma que os cursos técnicos, de grau médio. Essa graduação tem sua moldagem a partir de demandas econômicas e de necessidades no mundo do trabalho.

No Brasil, a expressão 'educação tecnológica' diz respeito à formação de nível superior de curta duração voltada para a capacitação para as profissões, sobretudo na área industrial, enquanto a 'educação técnica' se refere à formação profissional de nível médio (Schwartzman, 2005).

Os cursos superiores de tecnologia têm demonstrado uma significativa capacidade de adequação ao novo contexto do ensino superior brasileiro. Ofertados em um período de tempo entre dois e três anos, portanto menor que os bacharelados e as licenciaturas, os cursos tecnológicos tornam possível, para uma enorme parcela da população, a formação superior com 
menos custo e grande afinidade às necessidades das organizações empresariais no Brasil. Isso fez com que essa modalidade de graduação tivesse elevada procura e crescimento, nos últimos cinco anos (Rosetti, 2011).

Em cumprimento à Portaria no 413, de 11 de maio de 2016, o MEC instituiu o Catálogo Nacional dos Cursos Superiores de Tecnologia. O Catálogo regulamenta a oferta de cursos superiores de tecnologia, inspirado nas Diretrizes Curriculares Nacionais (DCN) e em sintonia com a dinâmica do setor produtivo e as expectativas da sociedade. O Catálogo Nacional dos Cursos Superiores de Tecnologia (CST) serve de base para os processos de regulação e supervisão da educação superior tecnológica e para o Exame Nacional de Desempenho dos Estudantes (Enade). 0 Catálogo dispõe sobre denominações de 134 cursos superiores de tecnologia (organizados em 13 eixos tecnológicos), descrições sintéticas do perfil do egresso, carga horária mínima e infraestrutura para o funcionamento desses cursos (Brasil, 2016).

O rol de cursos constante no Catálogo não esgota todas as possibilidades de oferta de cursos de graduações tecnológicas no País, admitindo-se, conforme estabelece o Decreto no 5.773/06, em seu art. 44, cursos experimentais de oferta regular, porém com outras denominações (Brasil, 2006).

É o caso do Curso Superior de Tecnologia em Serviços Jurídicos. Embora seja ofertado por muitas instituições de ensino tanto públicas como privadas ainda não faz parte do Catálogo Nacional dos Cursos Superiores de Tecnologia. O objetivo geral do Curso Superior de Tecnologia em Serviços Jurídicos é formar profissionais qualificados para o exercício das atividades pertinentes à organização e suporte de serviços judiciários, atendendo a uma demanda que é existente de colaboradores de nível superior com formação adequada para o apoio aos órgãos jurídicos. $\mathrm{O}$ curso objeto desse estudo é ofertado na modalidade a distância.

A educação a distância surge neste quadro de mudanças como mais um modo regular de oferta de ensino e assume funções de crescente importância, principalmente no ensino póssecundário, seja na formação inicial (ensino superior regular), seja na formação continuada, cuja demanda cresce de modo exponencial, em virtude do crescimento acelerado da tecnologia e do conhecimento.

Em virtude desse crecimento, considerando que a aprendizagem deve ocorrer de forma significativa, emerge a necessidade de identificar as dificuldades dos discentes nesse processo, uma vez que com a identificação das dificuldades é possível propor medidas para tornar o processo cognitivo mais eficaz para que o conhecimento seja, de fato, apropriado pelos discentes.

É de fundamental importância compreender quais as dificuldades que os discentes em EaD encontram e as necessidades que apresentam, para conhecer o aprendiz e viabilizar práticas educacionais que contribuam com a aprendizagem.

Em 1963, Wedemeyer chamava a atenção para o fato que nem todos os alunos serão capazes de ter sucesso no ensino por correspondência, uma vez que essa não era uma modalidade de ensino fácil. Como obstáculos para o sucesso da aprendizagem destacava: a) o desenvolvimento de interesse pela tarefa, a motivação, e a preparação para o estudo, uma vez que é muito difícil iniciar a EaD, e a taxa de desistência antes do início do curso é até hoje muito alta; b) a compreensão da estrutura do conteúdo a ser estudado; c) a aprendizagem de habilidades de pensamento analíticas; e d) a autoavaliação da aprendizagem (Keegan, 1996).

Silva e Sá (1997), afirmam que há dois tipos de fatores que os alunos geralmente atribuem às dificuldades de aprendizagem: fatores externos à aprendizagem (como o método de ensino ou o clima desfavorável no qual a aprendizagem aconteceu) e fatores internos (como a falta de conhecimentos prévios e o nível de ansiedade). As autoras resumem as principais dificuldades encontradas em três áreas: o tempo e a organização do estudo (estudo nas vésperas das avaliações, tempo de estudo insuficiente, falta de planejamento das atividades escolares); as estratégias cognitivas (utilização do mesmo método de estudo para todas as disciplinas, não-resolução de dúvidas, incapacidade para autoavaliar a compreensão das matérias, dificuldade em relacionar a 
informação e realizar inferências) e, por fim, a motivação (falta de persistência na realização de trabalhos e exercícios, ausência de interesse pela aprendizagem).

As autoras consideram as estratégias cognitivas como operações ou atividades conscientes e intencionais adotadas para a realização de uma determinada tarefa. Sua aplicação requer que o aprendiz tenha conhecimento e reflita sobre os seus próprios processos mentais, dando-lhe autonomia e regulação dos seus próprios comportamentos escolares para, enfim, aprender a aprender (Silva \& Sá, 1997).

Outra dificuldade é a falta de autonomia e de autodireção na aprendizagem. Muitos exercem um papel passivo na aprendizagem, não porque preferem assim, mas porque não foram acostumados a exercer um papel ativo. A esse respeito Malcolm Knowles destaca que "é um fato trágico que a maioria de nós saibamos apenas como ser ensinados; nós não aprendemos como aprender" (Knowles, 1975 como citado em Rabello, 2007, p. 19).

Fernandes (2017) afirma que o grande aliado da educação nos últimos anos pode ser considerado o desenvolvimento e a disseminação das Tecnologias digitais da Informação e Comunicação (TDIC), que possibilitaram um expressivo aumento da oferta de EaD. Contudo, apesar dessa modalidade de ensino proporcionar flexibilidade nos estudos e atender as mais remotas regiões, ela tem exigido uma maior autonomia do discente, especialmente, no que se refere à necessidade de autorregulação no seu processo de aprendizagem.

Castro et al. (2001) afirmam que o aprendiz que optar por se atualizar por meio de um programa de EaD deverá estar pronto para assumir uma nova postura perante a aprendizagem, uma postura ativa e crítica, além do desenvolvimento de hábitos de estudo sistemáticos e eficientes. Além disso, os autores descrevem características comportamentais necessárias ao desenvolvimento do aprendiz na $\mathrm{EaD}$, tais como: estar motivado para aprender; ter constância, perseverança e responsabilidade; ter hábito de planejamento; ter visão de futuro; ser proativo; e ser comprometido e autodisciplinado.

Jonaitis (2005, tradução nossa), adverte para a necessidade de o discente estar informado sobre as habilidades que essa modalidade de ensino demanda do aprendiz desde o ato de inscrição no curso a distância. Afirma ainda, que muitos aprendizes possuem ideias errôneas de educação a distância, devido à distância entre o produto efetivo e o produto vendido na EaD. Muitas vezes, o que é reforçado é a conveniência e a flexibilidade, ao invés das dificuldades que muitos aprendizes encontram.

É facilmente perceptível que muitos se inscrevem em cursos de EaD com a ilusão de que essa modalidade lhe exigirá menos tempo de estudo e comprometimento pessoal, ou mesmo, que será mais fácil que a educação tradicional (Jonaitis, 2005, tradução nossa). Este ainda é uma das ideias pré-concebidas a serem vencidos pela EaD, que muitas vezes é "vendida" como um curso para quem não tem tempo de estudar. Embora na EaD haja a possibilidade de flexibilidade de tempo e local de estudo, não sendo necessário o deslocamento até uma sala de aula tradicional em um dia e horário específicos, os níveis de comprometimento e dedicação devem ser maiores; para o sucesso da aprendizagem a distância, habilidades de gerenciamento de tempo e autodisciplina são fatores essenciais.

Considerando-se a importância do processo de aprendizagem na modalidade a distância sem as barreiras das dificuldades, pergunta-se: quais as dificuldades que os aprendizes encontram na sua formação a distância em um curso de tecnologia em serviços jurídicos na modalidade EaD?

Após busca realizada na base de dados do Instituto Brasileiro de Informação em Ciência e Tecnologia (IBICT), na Biblioteca Digital Brasileira de Teses e Dissertações (BDTD), com a utilização das palavras-chaves: dificuldades; educação a distância; ensino e aprendizagem em abril de 2020. Foram encontradas 11 teses e/ou dissertações, disponíveis para leitura, que abordavam o tema em seus estudos. 
Destas 11 publicações, quatro (04) trataram das dificuldades no processo de ensino e aprendizagem de alunos em cursos presenciais, embora um dos critérios colocados no filtro da pesquisa fosse a palavra-chave: Ensino a Distância. Estes quatro estudos foram publicados nos anos de 2012, 2013, 2016 e 2019. Um (01) estudo tratava da identificação das principais dificuldades técnicas e pedagógicas na utilização do ambiente virtual de aprendizagem Moodle por parte dos professores de uma instituição de nível superior e foi publicado no ano de 2012. Um (01) estudo tratava da análise das compreensões dos alunos-professores em relação ao portfólio de aprendizagens e a síntese reflexiva no processo de aprendizagem do curso de Pedagogia na modalidade EaD e foi publicado no ano de 2017. Cinco (05) estudos trataram da percepção de alunos sobre as dificuldades no processo de ensino e aprendizagem em diversos cursos superiores na modalidade a distância, duas nos anos de 2009 e 2017 e três em 2013.

Pesquisadores como Burian (2009), Nascimento (2013), Silveira (2013), Reis (2013) e Silva (2017) apresentaram um panorama da EaD no Brasil e analisaram as dificuldades relatadas pelos discentes de cursos superiores na modalidade a distância. Existe uma concordância entre os autores no sentido de que a tarefa é complexa e envolve uma multiplicidade de fatores a serem analisados. Dentre eles, destaca-se a necessidade de formação dos envolvidos para o uso das tecnologias disponíveis, além das questões relacionadas à viabilidade técnica, esforço pessoal e suporte.

Não se encontrou nenhuma pesquisa sobre as dificuldades de ensino e aprendizagem no ensino jurídico. Assim, justifica-se a pesquisa realizada que tem como objetivo geral, descrever e analisar perspectivas de discentes sobre o processo de ensino e aprendizagem em um curso de tecnologia em serviços jurídicos na modalidade EaD, com ênfase aos problemas de ensino e aprendizagem citados pelos participantes.

\section{METODOLOGIA}

O estudo foi aprovado pelo Comitê de Ética em Pesquisa (CEP) sob o registro CAAE 30054120.7.0000.0108 parecer de aprovação n. 3.967.381 como um dos objetivos do projeto intitulado "As múltiplas linguagens no uso das tecnologias digitais de informação e comunicação no processo de ensino e aprendizagem de acadêmicos de cursos superiores híbridos". Realizou-se uma pesquisa descritiva com abordagem na análise dos dados quantitativa e qualitativa. A pesquisa foi realizada no $O$ Centro Universitário $X$ de Londrina (UXL) é uma Instituição de ensino privada mantida por x, com o Conceito Institucional (Cl) 4 (quatro). Está localizada na cidade de Londrina - Paraná. O Centro Universitário possui em seu portfólio 19 cursos presenciais, 05 híbridos, 23 com metodologias totalmente a distância onde os alunos vão à instituição apenas para a realização das avaliações.

Foram convidados a participar alunos dos 2ำ, 3ํ e 4을 semestres do curso de Serviços Jurídicos de um Centro Universitário privado de uma cidade do norte do Paraná. O questionário foi distribuído a todos os alunos matriculados nos três últimos semestres do curso. Dos 60 alunos matriculados em julho de 2020, 29 alunos (48,33\% do total de alunos) responderam ao questionário. O questionário preenchido sem a presença do pesquisador foi elaborado a partir de uma adaptação dos estudos de Rabello (2007) que contemplou um questionário validado sobre o tema de dificuldades no processo de aprendizagem. A autora Rabello (2007) estabeleceu no instrumento de coleta de dados variáveis relacionadas a: (a) identificar os hábitos de estudo dos alunos antes e durante o estudo em EaD; (b) identificar as dificuldades encontradas por eles ao longo do primeiro semestre do curso de graduação a distância; (c) estudar a relação, eventualmente existente, entre hábitos de estudo e dificuldades de aprendizagem.

Foram utilizadas as questões $8,9,10,11,12,13,16,17,18,19,20,21,26$ e 27 do instrumento de Rabello (2007) as demais foram criadas com base nas especificidades do curso estudado. Após a adaptação do questionário da autora obteve-se um instrumento composto por 27 questões que 
abrangeu perguntas sobre: o perfil socioeconômico dos alunos; a formação dos mesmos; hábitos de estudo; dificuldades de aprendizagem; e utilização de tecnologias.

O questionário contou também com uma escala de atitude do tipo Likert com 18 afirmativas referentes ao desempenho acadêmico dos aprendizes e sua gerência da aprendizagem e à utilização de recursos oferecidos. Foram incluídas duas questões abertas, nas quais os alunos puderam se expressar livremente sobre a maior dificuldade que encontraram no estudo a distância e o que poderia ser feito para ajudá-los a aprimorar sua aprendizagem.

A partir das respostas abertas do questionário utilizou-se as perspectivas de Rabello (2007) para elaboração das categorias de análise. A autora categorizou as dificuldades de aprendizagem de alunos em: (1) dificuldades pessoais: referentes às dificuldades relacionadas diretamente ao aluno e seu processo de aprendizagem e (2) design instrucional: referentes às dificuldades relacionadas ao modelo instrucional do curso.

\section{RESULTADOS E DISCUSSÃO}

Os dados são apresentados subdivididos em: perfil dos respondentes; uso de tecnologias no processo de ensino e aprendizagem utilizados no curso; processo de ensino e aprendizagem; dificuldades no processo de aprendizagem e sugestões para a melhoria da aprendizagem.

\section{Perfil dos respondentes}

Os dados referem-se ao perfil sociodemográfico dos respondentes em relação a faixa etária; gênero; estado civil; filiação; renda e escolaridade anterior ao curso.

Dos 29 respondentes ao questionário, 24,1\% (7) afirmaram estar na faixa etária de até 30 anos. 34,5\% (10) possuem entre 31 e 40 anos. Na faixa etária dos 41 a 50 anos estão 10,3\% (3) dos respondentes e por fim, 31\% (9) dos respondentes possuem de 51 a 60 anos. Considerando esses percentuais verifica-se que $65,8 \%$ (22) dos alunos informaram ter entre 31 e 60 anos, o que evidencia um público mais maduro e com poucos jovens.

Esse dado está em conformidade com o Censo EAD.BR (Associação Brasileira de Educação a Distância [ABED], 2018) que revelou que os alunos de cursos a distância tendem a ser mais velhos, com uma predominância na faixa entre 26 e 40 anos (76,3\%). Segundo esse relatório, os alunos que mais frequentemente optam por cursos totalmente a distância estão nas faixas entre 26 e 30 anos $(39,3 \%)$ e 31 e 40 anos (37\%), que, juntas, compõem 76,3\% do alunado dessa modalidade. Os dados apresentados não surpreendem, visto que, em geral, esse público já está inserido no mercado de trabalho e tem compromissos relativos à subsistência de sua família. A escolha por essa modalidade, provavelmente ocorre em virtude da flexibilidade de horário e de acesso possibilitada pela EaD. Com relação ao gênero, dos 29 alunos respondentes verificou-se que $27,6 \%$ (8) são mulheres e $72,4 \%$ (21) são homens.

Este dado obteve variação com relação aos dados obtidos no Censo Inep - Instituto Nacional de Estudos e Pesquisas Educacionais Anísio Teixeira (2019), última edição do levantamento, que revelaram que as mulheres representam $55,7 \%$ do corpo discente.

Os respondentes (29) são em sua maioria casados totalizando 58,6\% (17) e 41,4\% (12) declararam-se solteiros. Essa predominância de alunos casados foi observada por Fernandes (2017) em seu estudo sobre o perfil de aprendizagem autorregulada dos alunos matriculados em um curso de Pedagogia a distância que encontrou $55,5 \%$ de casados, 38,21\% solteiros, $4,25 \%$ divorciados, $1,39 \%$ separados e $0,49 \%$ viúvos.

Com relação a posse de filhos, $48,3 \%$ (14) dos respondentes afirmaram que não possuem filhos, $41,4 \%$ (12) dos respondentes possuem filhos e residem de forma conjunta e $10,3 \%$ (3) dos respondentes possuem filhos, porém, não vivem na mesma residência. 
Lott et al. (2018) evidenciaram que na amostra de seu estudo, com objetivo de propor e testar um modelo teórico para investigar fatores que influenciam a persistência e evasão de alunos em cursos de administração e ciência da computação a distância, possuía 58,3\% de respondentes sem filhos e $41,7 \%$ de respondentes com filhos. Segundo os autores, na conclusão de seu estudo, o aumento no número de filhos dificulta a permanência do aluno no curso.

Umekawa (2014) afirma que para os participantes casados e com filhos, os atributos internos do sujeito que aprende, referentes a autorregulação, são de grande relevância para sua permanência no curso. Ainda, afirma que para tais indivíduos, esse específico arranjo familiar (presença de filhos e cônjuge) implique em numerosos compromissos que, para não dificultarem a continuidade da ação instrucional, dependerão das características pessoais dos mesmos - em termos de persistência e comprometimento com suas incumbências acadêmicas.

Em nossa pesquisa a maioria dos alunos trabalham e contribuem com mais $50 \%$ da renda familiar $(62,1 \%$ - 18 alunos), enquanto $17,2 \%(17,2)$ dos respondentes afirmaram contribuir com até $20 \%$ e $20,7 \%$ (6) dos respondentes afirmaram que seu trabalho contribui de $20 \%$ a $50 \%$ com a renda familiar.

Esses dados sugerem, conforme Schnitman (2010), que a EaD é uma oportunidade de prosseguimento dos estudos para jovens adultos, que são trabalhadores e possuem uma família. Isso se deve ao fato dessa modalidade de ensino facilitar-lhes o acesso pela flexibilidade de horários e oferecer-lhes autonomia em desenvolver um cronograma de estudo de acordo com sua disponibilidade de tempo.

Nesse estudo a maioria dos respondentes (51,7\% - 15 alunos) está cursando a sua primeira graduação e 48,3\% (14) possuem uma graduação anterior .Nos estudos de Munhoz (2018), cujo objetivo foi analisar como ocorre a autorregulação, por meio do uso de estratégias de aprendizagem, com a participação de 12 alunos de diferentes cursos na modalidade a distância, em relação à escolaridade desses alunos de ensino superior, $91 \%$ dos respondentes disseram que estavam cursando a graduação pela primeira vez.

No estudo de Fernandes (2017), que analisou o perfil de aprendizagem autorregulada dos alunos matriculados em um curso de Pedagogia a distância, 91,4\% da amostra cursavam a primeira graduação. No trabalho de Godoi e Oliveira (2016), que teve como objetivo conhecer o perfil de alunos de graduação a distância e discutir o estilo de aprendizagem mais favorável para a sua formação, a maioria cursava sua primeira graduação, ou seja, os que só tinham o Ensino Médio perfizeram $76,2 \%$ do total.

Nesse questionamento houve um distanciamento com os percentuais de outras pesquisas. Possivelmente em razão de que uma das características do curso superior de tecnologia em Serviços Jurídicos é seu público-alvo, voltado para profissionais que já atuam no mercado, tais como em: escritórios de advocacia, prepostos de grandes empresas, contadores, administradores e gestores de recursos humanos que precisam do conhecimento jurídico para execução do seu trabalho.

Sobre a afirmativa 'A falta de conhecimentos prévios prejudicou minha compreensão dos conteúdos'. Um respondente $(3,4 \%)$ concordou totalmente com a afirmação e um respondente $(3,4 \%)$ concordou parcialmente com a afirmação. $13,8 \%$ dos respondentes, ou seja, 4 alunos, nem concordaram e nem discordaram e $17 \%$ dos alunos discordaram parcialmente da afirmação e por fim, 61,2\% dos alunos discordaram totalmente de tal afirmação. Considerou-se como conhecimentos prévios o conhecimento dos termos técnicos utilizados na linguagem jurídica, o manuseio das legislações, hábitos de leitura de materiais teóricos e utilização de TDIC.

Andrade (2009) realizou uma pesquisa sobre as razões para a procura por um CST pelos estudantes, os resultados apontaram como três principais razões para a escolha do curso: perspectiva de inserção laboral após a conclusão do curso, valorização social do diploma e valorização das características de especialização do currículo e de formação mais prática. Jucá, 
Oliveira e Souza (2010, pp 2-3) consideram a criação de cursos superiores tecnológicos um avanço na educação superior brasileira:

[...] o tecnólogo, esse profissional de nível superior, deverá receber uma sólida formação científica, com espectro de atuação mais específico e que lhe proporcione uma compreensão teórica e prática das atividades que irá executar, tornando-o apto a desenvolver, de forma plena, uma determinada área profissional.

Ao analisar esses estudos, relacionando-os ao número de respondentes que possuem outra graduação, estão inseridos no mercado de trabalho e que possuem conhecimento prévio sobre o curso verifica-se que muitos buscam atualizar suas formações.

\section{O uso de tecnologias no processo de ensino e aprendizagem utilizados no curso}

No curso superior de tecnologia em Serviços Jurídicos EaD são utilizadas tecnologias diversas no ambiente virtual de aprendizagem (AVA) denominado Canvas, tais como: editores de texto, ferramentas de reprodução de vídeo, ferramentas de webconferência, arquivos em PDF, chat, fórum, portfólio.

O Canvas é uma plataforma baseada em nuvem, acessível a professores, alunos e gestores por meio da Web, com o diferencial de ser um software aberto, permitindo que diversos aplicativos, soluções e programas educacionais criados por outras empresas sejam facilmente integrados durante o desenvolvimento de cursos e módulos. Além disso, como está baseado na nuvem, seus recursos são atualizados automaticamente e uma mesma versão é disponibilizada para todos os usuários acessarem a partir de qualquer lugar e dispositivo.

Quando perguntados 'se possuíam familiaridade com a utilização do computador' a resposta foi unânime, todos os alunos afirmaram que possuem familiaridade. No entanto, quando o questionamento se deu sobre 'a dificuldade na utilização do AVA' a resposta não se manteve unânime.

$3,4 \%$, ou seja, um aluno concordou plenamente com a afirmação de que teve dificuldades em utilizar o AVA. 10,3\% concordaram parcialmente. 6,9\% não concordaram e nem discordaram provavelmente por duas razões: não entenderam a pergunta ou não souberam responder. Discordaram parcialmente $24,1 \%$ dos respondes e por fim, $55,2 \%$ dos respondentes discordaram da afirmação de que tiveram dificuldades na utilização da plataforma.

No estudo de Mota (2014) o cursista deveria apontar quais dos fatores entre eles, o domínio do AVA, dificultaram seu desempenho no curso. Pelas respostas dos alunos, foi identificado que: para $69 \%$ o domínio do AVA não dificultou seu desempenho e $22 \%$ dos cursistas revelaram que o domínio do AVA dificultou pouco seu desempenho.

Tal observação também se verifica nas respostas aos questionamentos de domínio na utilização das ferramentas do word, de arquivos em PDF, de ferramentas de execução de vídeo e de webconferência.

Sobre o Word, $69 \%$ dos respondentes concordaram plenamente com a afirmação 'Eu tenho domínio na utilização das ferramentas do word'. $20,7 \%$ dos alunos concordaram parcialmente com a afirmação de que possuem familiaridade com a utilização da ferramenta e 10,3\%, ou seja, 3 alunos disseram que não concordam e nem discordam com a questão possivelmente por não terem compreendido a pergunta ou por não terem interesse em participar respondendo essa questão.

Os dados do estudo apresentam similaridade com o realizado por Aquino e Mazzafera (2018) sobre o domínio de tecnologias digitais na percepção de alunos ingressantes e concluintes do curso de ciências contábeis na modalidade presencial da Universidade Estadual de Londrina em relação ao domínio do editor de texto word. 
'Sobre o domínio na utilização de arquivos em $\mathrm{PDF}_{2}$, conhecimento necessário para salvar um documento nesse formato e utilizar os recursos desse programa, dentre os alunos respondentes, $72,4 \%$ concordaram plenamente com a afirmação, $20,8 \%$ concordaram parcialmente com a afirmação. 3,4\%, ou seja, um aluno não concordou e nem discordou da afirmação e por fim, 3,4\% (um aluno) discordou parcialmente com a afirmativa.

Com relação a afirmação: 'possuo domínio das ferramentas de execução de vídeo',_65,5\% dos alunos concordaram plenamente. $20,7 \%$ dos respondentes concordaram parcialmente. $10,4 \%$, ou seja, três alunos não concordaram e nem discordaram da afirmação e um aluno $(3,4 \%)$ discordou totalmente

São realizados, no mínimo, dois encontros on-line com os professores por bimestre em cada disciplina do curso pesquisado, assim, os alunos foram questionados em relação ao 'domínio das ferramentas de webconferência' e $55,2 \%$ dos respondentes concordaram plenamente que possuem esse domínio. 20,7\% concordaram parcialmente com a afirmação. Não compreenderam ou não quiseram participar da questão $13,8 \%$, pois não concordaram e nem discordaram. 6,9\% discordaram que possuem domínio das ferramentas e 3,4\% discordaram totalmente.

Observando-se os dados coletados é possível perceber que apesar dos respondentes afirmarem de forma unânime que possuem familiaridade com a utilização do computador, quando questionados sobre o domínio dos programas e ferramentas como AVA, word, PDF, execução de vídeo e webconferência, frequentemente utilizados nas aulas, muitos alunos discordam da afirmativa de que dominam a utilização das ferramentas.

Na pesquisa de Suguimoto et al. (2017) sobre avaliação do letramento digital de alunos ingressantes do ensino superior, os autores abordam que o ensino superior apresenta situações que demandam um processo de construção de conhecimento que proporcione autonomia no processo de apreender, para que se efetivem as finalidades desse nível no Brasil, em conformidade com o que está preconizado na Lei de Diretrizes e Bases da Educação Nacional (Lei $n^{\circ}$ 9.394/1996). Nesse cenário, o conhecimento e o domínio de ferramentas de TDIC (Tecnologia Digitais de Informação e Comunicação) são fundamentais para o desenvolvimento de estratégias de ensino que se traduzam na formação de profissionais capazes de atuar na construção e no aprimoramento da sociedade brasileira. De modo específico, numa sociedade que se quer moderna, são imperativas as ações para a diminuição dos índices de dificuldades computacionais, comunicacionais e informacionais (Suguimoto et al., 2017).

\section{O Processo de ensino e aprendizagem}

No processo de ensino e aprendizagem verificou-se quais ferramentas os respondentes utilizam e a quem recorrem quando estão diante de dúvidas.

Diante da afirmação: "Eu procurei pensar sobre minhas dificuldades e melhores maneiras de resolvê-las", 65,5\% dos alunos respondentes concordaram plenamente com assertiva. 27,6\% concordaram parcialmente com a afirmação. 3,4\%, ou seja, um aluno, discordou parcialmente e $3,4 \%$, ou seja, um aluno discordou totalmente.

Munhoz (2017) cita a teoria de Knowles de que a demonstração de autonomia deve ser inerente ao aprendiz adulto, uma vez que a dependência é uma característica da criança.

Além disso, o estudo encontra evidências de que alunos que se percebem como autodisciplinados possuem maiores chances de permanecer no curso, uma vez que a EaD requer um nível elevado de disciplina, organização, iniciativa, autonomia e motivação dos alunos (Moore \& Kearsley, 2008).

Os respondentes foram questionados se 'buscavam ajuda com colegas mais experientes para resolver suas dificuldades'. As respostas a esse quesito foram: 10,3\% concordaram plenamente com a assertiva; $27,6 \%$ dos respondentes concordaram parcialmente; $20,7 \%$ dos alunos não 
concordaram e nem discordaram; 17,2\% discordaram parcialmente e 24,1\% discordaram totalmente da afirmação.

Os resultados coincidem com os estudos de Rabello (2007) que identificou as dificuldades relacionadas à aprendizagem encontradas pelos alunos de graduação em educação a distância, a pesquisadora relacionou os alunos que tiraram boas notas e os alunos que não tiraram boas notas e no resultado de sua pesquisa, dentre os alunos que afirmaram que tiraram boas notas $61 \%$ concordaram plenamente ou parcialmente que procuraram a ajuda de colegas mais experientes para solução de dúvidas. $8 \%$ dos respondentes se mantiveram neutros, ou seja, não concordaram e nem discordaram e $31 \%$ discordaram parcialmente ou totalmente com a assertiva.

Nos estudos de Rabello (2007) dentre os alunos que afirmaram que não tiraram boas notas, $48 \%$ concordaram plenamente ou parcialmente com a assertiva de que haviam buscado a ajuda de colegas mais experientes para a solução de dúvidas, $8 \%$ mantiveram-se neutros e $44 \%$ dos respondentes discordaram totalmente ou parcialmente.

Em nossa pesquisa, diante da assertiva: 'Eu busquei tutores ou coordenadores para resolver minhas dificuldades', quanto ao modelo instrucional e de secretaria (financeiras, solicitação de documentos, dificuldades de acesso à plataforma, links quebrados etc.), $41,4 \%$ dos alunos concordaram plenamente com a afirmação, 31\% concordou parcialmente, $13,8 \%$ não concordaram e nem discordaram, 3,4\% discordou parcialmente e 10,3\% discordou totalmente com a questão.

Com relação a solução de dúvidas de conteúdo, diante da afirmação: 'Eu utilizei a tutoria a distância sempre que tive dúvidas durante o estudo' ${ }_{2} 48,3 \%$ dos respondentes concordaram totalmente, $27,6 \%$ concordaram parcialmente, $13,8 \%$ responderam que não concordam em nem discordam e $10,3 \%$ discordaram totalmente.

Tanto a assertiva sobre as dificuldades concernentes ao modelo instrucional como a assertiva de solução de dúvidas de conteúdo, tiveram respostas bem semelhantes por parte dos discentes. A maioria dos alunos concordou plenamente ou parcialmente que procurou a tutoria quando estavam diante de dificuldades ou solução de dúvidas. Porém, 10,3\% dos alunos em ambas as assertivas discordaram totalmente da afirmação.

Observa-se que 10,3\% dos respondentes não procuraram o tutor ou coordenador do curso em casos de dificuldades com o modelo instrucional e, não procuraram o tutor em casos de dúvidas concernentes ao conteúdo.

A não resolução de dúvidas, segundo Silva e Sá (1997) faz parte das principais dificuldades do processo de aprendizagem. As autoras categorizam essas dificuldades em três grandes áreas: 0 tempo e a organização do estudo; estratégias cognitivas; e, por fim, a motivação.

Essa ausência de resolução de dúvidas, segundo as autoras, faz parte das dificuldades em estratégias cognitivas (utilização do mesmo método de estudo para todas as disciplinas, nãoresolução de dúvidas, incapacidade para autoavaliar a compreensão das matérias, dificuldade em relacionar a informação e realizar inferências).

Em razão do principal objetivo do fórum de discussão ser a troca de experiências, solução de dúvidas e interação entre os alunos e o professor/tutor, foi colocado no questionário a seguinte assertiva: 'Eu participei dos fóruns de discussão na plataforma', 69\% dos respondentes concordaram plenamente, $20,7 \%$ concordaram parcialmente, 6,9\% mantiveram-se neutros e 3,4\% discordaram totalmente.

No estudo de Rodrigues (2013) que teve por objetivo analisar o fórum (interface educacional) utilizado no processo de avaliação da aprendizagem em $\mathrm{EaD}$, uma de suas conclusões foi que o fórum é sem dúvida, uma poderosa ferramenta utilizada atualmente para avaliar a aprendizagem dos alunos e identificar dificuldades no ambiente virtual. É um novo instrumento de avaliação que possibilita ao aluno, a construção do seu próprio caminho e da sua própria aprendizagem gerando autonomia. É um ambiente que promove a cooperação, a análise crítica, o 
diálogo, a discussão e a autoavaliação. Estas são características essenciais, para que o alunado esteja preparado para enfrentar os desafios presentes na Era da Informação e da globalização.

Diante da assertiva: 'Eu tenho controle sobre minha aprendizagem', 75,9\% dos respondentes concordaram plenamente com a afirmação. 20,7\% concordaram parcialmente e 3,4\% ou seja, um aluno, não concordou e nem discordou. Nessa assertiva nenhum aluno assinalou a opção discordo parcialmente ou discordo totalmente.

Diante desses dados verifica-se que os respondentes entendem sua responsabilidade e seu controle sobre a sua aprendizagem. A importância do desenvolvimento da autonomia vai além da "sala de aula". Com os avanços tecnológicos o lifelong learning se tornou obrigatório e consequentemente o desenvolvimento da autonomia também.

O aprendiz autônomo é aquele que não necessita de ajuda para formular objetivos de aprendizagem, identificar fontes de informação e avaliar seu próprio desempenho. Ressalta que o sucesso da aprendizagem na $\mathrm{EaD}$ depende da extensão na qual o aluno pode estudar sem a interferência direta do professor, "o que é determinado por sua competência enquanto aprendiz autônomo e autodirigido" (Moore, 1980, p. 22).

Diante da afirmação: 'Eu estudei semanalmente as aulas solicitadas e procurei esclarecer dúvidas', 51,7\% concordaram plenamente com a assertiva. 44,8\% concordaram parcialmente e somente um aluno $(3,4 \%)$ discordou parcialmente.

Os dados coletados com relação a frequência de estudo vão de encontro a pesquisa de Rabello (2007) em que 33\% dos alunos afirmaram que estudaram 3 vezes ou mais por semana; $29 \%$ dos alunos disseram estudar diariamente; $23 \%$ dos alunos afirmaram estudar 1 ou 2 vezes por semana; $7 \%$ estudaram apenas aos finais de semana; $6 \%$ dos alunos estudaram alguns dias por mês e por fim, $2 \%$ afirmaram que estudaram somente às vésperas das provas.

Sobre a assertiva: 'Eu tive facilidade de estudar sozinho', 69\% dos respondentes concordaram plenamente; $27,6 \%$ dos alunos concordaram parcialmente e 3,4\% não concordou e nem discordou. Nessa afirmação nenhum aluno assinalou as opções discordo parcialmente ou discordo totalmente.

Apesar da maioria dos alunos (96,6\%) afirmarem que possuem facilidade para estudar sozinhos, diante da assertiva: 'Eu tive dificuldades com a organização do tempo para estudo', 13,8\% concordaram plenamente com a afirmação; $13,8 \%$ concordaram parcialmente; $10,3 \%$ mantiveramse neutros; $17,2 \%$ discordou parcialmente e $44,8 \%$ discordaram totalmente com a afirmação (Tabela 15).

Essa dificuldade relatada pelos alunos coincide com os estudos de Belloni (2012) que ressalta que muitos estudantes de cursos a distância encontram dificuldades para responder às exigências desse contexto da educação, ou seja, as necessidades de gerenciamento do tempo, planejamento e autodireção.

Diante da assertiva: 'Eu tive dificuldades com a linguagem jurídica utilizada nos materiais', 3,4\% ou seja, um aluno, concordou plenamente com a afirmação; 10,3\% dos respondentes concordaram parcialmente; $13,8 \%$ mantiveram-se neutros ao assinalar a opção "não concordo e nem discordo"; $31 \%$ discordaram parcialmente e $41,4 \%$ discordaram totalmente.

Observa-se que apenas $13,7 \%$ dos alunos concordaram plenamente ou parcialmente com a afirmação, percentual que nos chamou a atenção posto que a linguagem jurídica é de fato complexa.

Para compreensão da organização do estudo dos alunos, constou-se a assertiva: 'As orientações do Guia do Aluno me ajudaram a estudar'. Esse material é enviado ao aluno no início do curso e permanece disponível no decorrer. Nesse material o aluno encontra informações sobre o curso, avaliações, atividades acadêmicas complementares, calendário acadêmico e instruções de como estudar. 
$58,6 \%$ dos respondentes concordaram plenamente que as orientações do guia do aluno os ajudaram a estudar; $27,6 \%$ concordaram parcialmente; $6,9 \%$ não concordaram e nem discordaram da assertiva e 6,9\% discordaram totalmente .

De acordo com os dados obtidos na pesquisa, foi possível verificar que $86,2 \%$ dos respondentes utilizaram as orientações do material 'guia do aluno' para estudar.

Conforme destacado nos estudos de Rabello (2007) a autonomia do aprendiz e a autodireção da aprendizagem são dois fatores determinantes para o sucesso da aprendizagem. Embora a autonomia seja característica da idade adulta, ela não é adquirida automaticamente, mas desenvolvida. Por essa razão, a importância de disponibilizar aos alunos guias para orientação do estudo.

\section{Dificuldades no processo de aprendizagem}

Ao final do questionário haviam duas perguntas subjetivas. A primeira pergunta solicitava ao aluno para descrever as maiores dificuldades no estudo.

Essa pergunta foi respondida por 27 alunos que descreveram diferentes tipos de dificuldades relacionadas tanto ao modelo didático pedagógico quanto a dificuldades de cunho pessoal. Dentre as 27 respostas oito delas não foram categorizadas, pois seis respostas relatavam que não houve nenhum tipo de dificuldade e duas assertivas que trataram de questões pessoais que não poderiam ser categorizadas como dificuldades (um respondente não queria fazer prova presencial e o outro afirmou ter dificuldades para lembrar das datas da prova).

Utilizando como referência o estudo de Rabello (2007) as respostas dos 19 respondentes foram categorizadas em: (a) dificuldades pessoais (relacionadas diretamente ao aluno e seu processo de aprendizagem); e (b) design instrucional (relacionadas ao modelo instrucional do curso).

Essas categorias foram organizadas em subcategorias (Figura 1) em função das características das respostas. 
Figura 1. Categorias das dificuldades.

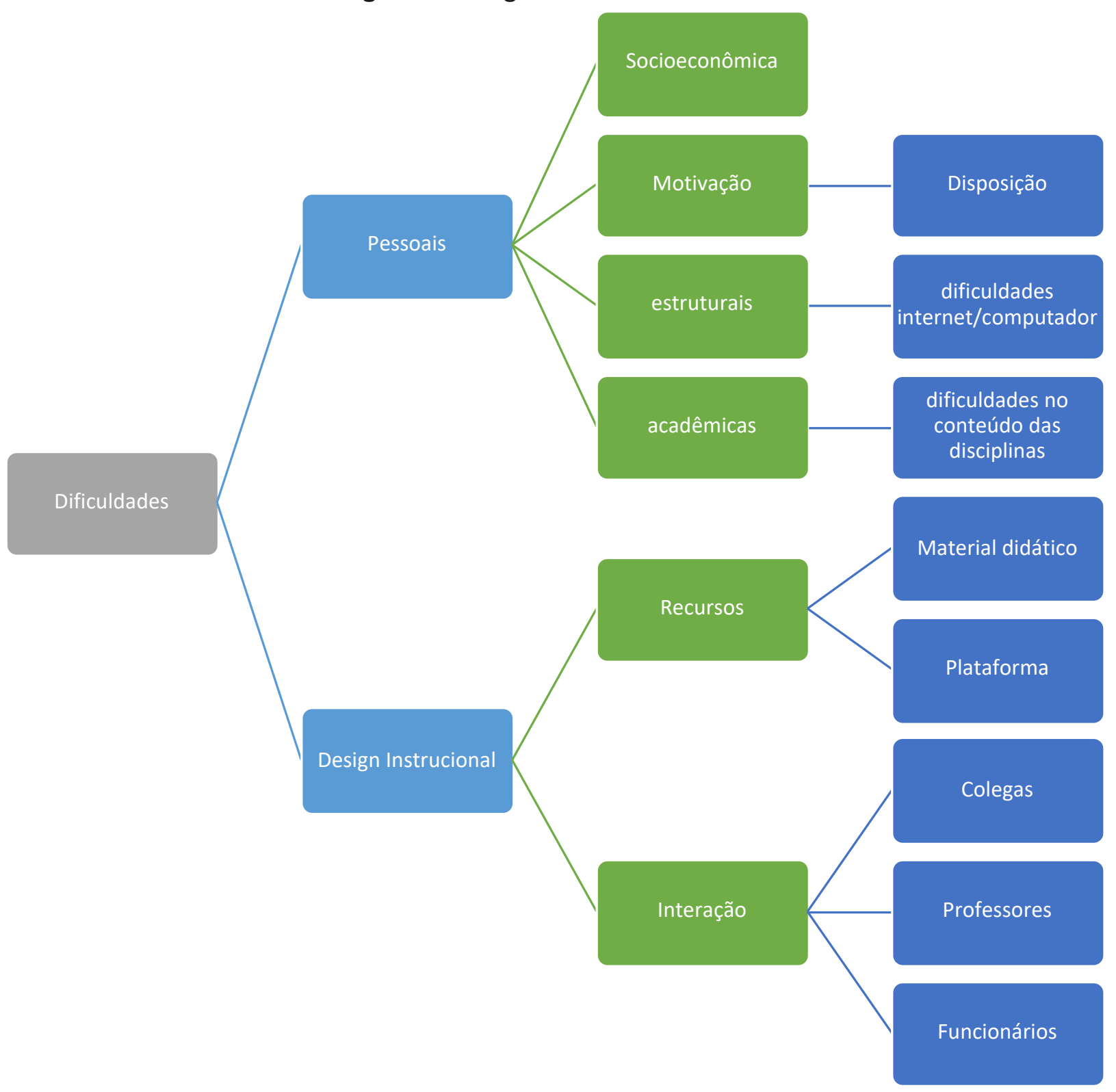

Fonte: dados da pesquisa (2020).

Em relação as dificuldades pessoais pode-se subdividi-las em:

a.1) Dificuldades de ordem econômica que referem-se a condições adversas ao estudo em que necessidades de trabalho, de atendimento à família e condições financeiras difíceis acarretam incompatibilidade de tempo disponível para compromissos profissionais e acadêmicos.

Verifica-se nas dificuldades relatadas pelos alunos que parte deles apresentaram dificuldades devido à falta de autonomia sobre o processo de aprendizagem, como exemplo, nas afirmações: "Conciliar trabalho e estudo" como descrito pelo participante: "Sem dúvidas, a maior dificuldade que tive foi a administração do tempo para estudar e dessa forma ter resultados melhores na avaliação. Já que eu me encontro em um ambiente familiar não muito bem estruturado e com pouco silêncio isso é muito determinante na minha concentração para produzir e estudar. Tirando alguns outros fatores, como responsabilidades domésticas, ter que trabalhar para ajudar nas despesas da casa."

a.2) Motivação para o estudo: ânimo, dedicação, foco, objetivo etc. Nessa categoria destacase a seguinte afirmação: "Vencer o cansaço e o sono são uma das maiores dificuldades". 
a.3) Dificuldades estruturais como falta de computador e de acesso à Internet. Os respondentes afirmaram que "A dificuldade em conciliar o meu tempo disponível com a questão da tecnologia, pois nem sempre a internet estava na velocidade que eu precisava, às vezes, quando vídeos, travam e, em outras, nem acesso consegui, o que atrasava os conteúdos". E ainda que "De início tive dificuldade para acessar a página por que está sem computador, depois que comprei fiquei mais tranquila e não tive nenhum impedimento para acessar as abas do portal".

a.4) Acadêmicas: dificuldades relacionadas ao estudo do conteúdo, seja pela dificuldade com uma disciplina específica, pelo relato de conteúdo teórico excessivo, ou pela linguagem jurídica.

Nessa categoria os respondentes fizeram relatos, como exemplos:

E1"A maior dificuldade até o momento foi a linguagem jurídica. Diante da sua relevância, a explicação detalhada de alguns conceitos se torna importante";

E2"(...) O conteúdo de algumas disciplinas era muito extenso e não tão fácil de aprender tão rapidamente";

E3"Foi o começo, pois foram várias dificuldades, até mesmo econômicas em alguns breves momentos, e também um universo novo que se abria sobre o mundo jurídico do qual eu nada sabia, ainda é tudo muito difícil principalmente na parte processual por ser mais abstrata e não praticada pela gente (...).";

E4"A minha maior dificuldade, consistia na assimilação do conteúdo para a revisão da avaliação, muita matéria para fazer a prova, tendo em vista, que era três ou quatro disciplinas ao mesmo tempo".

Design Instrucional: dificuldades relacionadas à utilização dos recursos instrucionais do curso, aspecto subdividido em outros quatro itens:

b.1) Recursos:

- Material didático: dificuldades relacionadas ao conteúdo e apresentação, materiais e recursos disponíveis na plataforma do curso; nessa categoria houveram algumas respostas nesse sentido, por exemplo: "O material disponibilizado pelos tutores deveria ser de uma forma mais didática".

- Plataforma: dificuldades relativas à utilização de materiais e recursos disponíveis na plataforma do curso na Web, além da dificuldade de acesso da própria plataforma, por esta conter arquivos muito pesados.

Nessa dificuldade um respondente fez a seguinte afirmação: "A maior dificuldade que encontrei foi me identificar com a plataforma e entender as noções de Direito devido ao pouco tempo dos vídeos postados pelos professores".

b.2) Interação: apesar do curso ser $100 \%$ on-line os alunos relataram a necessidade de interação com:

- Colegas: dificuldades em estudar sozinhos sem a presença de outros alunos. Nesta categoria houve o seguinte relato: "Senti falta da interação entre colegas e aulas mais aprofundadas sobre os temas estudados".

- Professores: alguns alunos relataram que gostariam de ter acesso e suas dúvidas respondidas diretamente pelo professor sem a intermediação do tutor. Um dos respondentes relatou: "maior interação entre aluno e professor".

- Funcionários: alguns alunos relataram dificuldades de acesso a funcionários no que se refere ao suporte de AVA. Nesta categoria foram feitas afirmações como: "Atendimento por parte dos funcionários" ou ainda "Talvez a interação por meio da caixa de mensagens que utilizei bem com a coordenadora, mas faltou um diálogo maior com os instrutores".

Após a categorização dos dados, apresenta-se uma síntese, com o percentual das dificuldades apresentadas (figura 1) e exemplificadas. 
A maior dificuldade apontada pelos alunos foi relacionada a dificuldades de cunho pessoal, que correspondeu a $57,8 \%$ das assertivas, enquanto $42,2 \%$ se referiram a dificuldades relacionadas ao design do curso pesquisado.

Nas dificuldades de ordem pessoal, predominam as dificuldades acadêmicas que perfizeram um total de $54,5 \%$ das dificuldades pessoais mencionadas, seguidas de dificuldades de ordem socioeconômica $(18,1 \%)$ e estruturais $(18,1 \%)$ que obtiveram a mesma porcentagem e dificuldades de motivação $(9,3 \%)$ (Tabela 1$)$.

Tabela 1. Principais dificuldades pessoais encontradas no estudo a distância.

\begin{tabular}{|c|c|c|}
\hline Subcategorias & Total de respostas & $\%$ \\
\hline a) Socioeconômica & 02 & $18,1 \%$ \\
\hline b) Motivação & 01 & $9,3 \%$ \\
\hline c) Estruturais & 02 & $18,1 \%$ \\
\hline d) Acadêmicas & 06 & $54,5 \%$ \\
\hline Total & 11 & $100 \%$ \\
\hline
\end{tabular}

Fonte: dados da pesquisa (2020).

A tabela 2 exibe os dados obtidos na análise das dificuldades relacionadas ao design instrucional do curso estudado. $50 \%$ das assertivas indicam que os recursos instrucionais foram a maior fonte de dificuldades. A ausência de interação entre colegas, professores e funcionários também constituiu o mesmo número de assertivas de dificuldade, totalizando $50 \%$ das assertivas.

Tabela 2. Principais dificuldades referentes ao design instrucional.

\begin{tabular}{|c|c|c|}
\hline Subcategorias & Total de respostas & $\%$ \\
\hline \multicolumn{3}{|c|}{ Dificuldades com os recursos instrucionais } \\
\hline a) Material Didático & 03 & $37,5 \%$ \\
\hline b) Plataforma & 01 & $12,5 \%$ \\
\hline Subtotal: & 04 & $50 \%$ \\
\hline \multicolumn{3}{|l|}{ Ausência de Interação } \\
\hline a) Colegas & 01 & 12,5 \\
\hline b) Professores & 01 & 12,5 \\
\hline c) Funcionários & 02 & 25 \\
\hline Subtotal: & 04 & $50 \%$ \\
\hline Total & 08 & $100 \%$ \\
\hline
\end{tabular}

Fonte: Dados da pesquisa (2020).

\section{Sugestões para a melhoria da aprendizagem}

Em relação as questões sobre o que poderia ser feito para ajudar na melhoria da aprendizagem e as sugestões foram obtidas 28 respostas. Dentre elas cinco não foram categorizadas pois não relatavam nenhuma sugestão de melhora no processo de ensino e aprendizagem (apenas elogiaram).

Apresenta-se, dessa forma as categorias oriundas dos 23 respondentes (Figura 2). 
Figura 2. Sugestões no processo de ensino e aprendizagem.

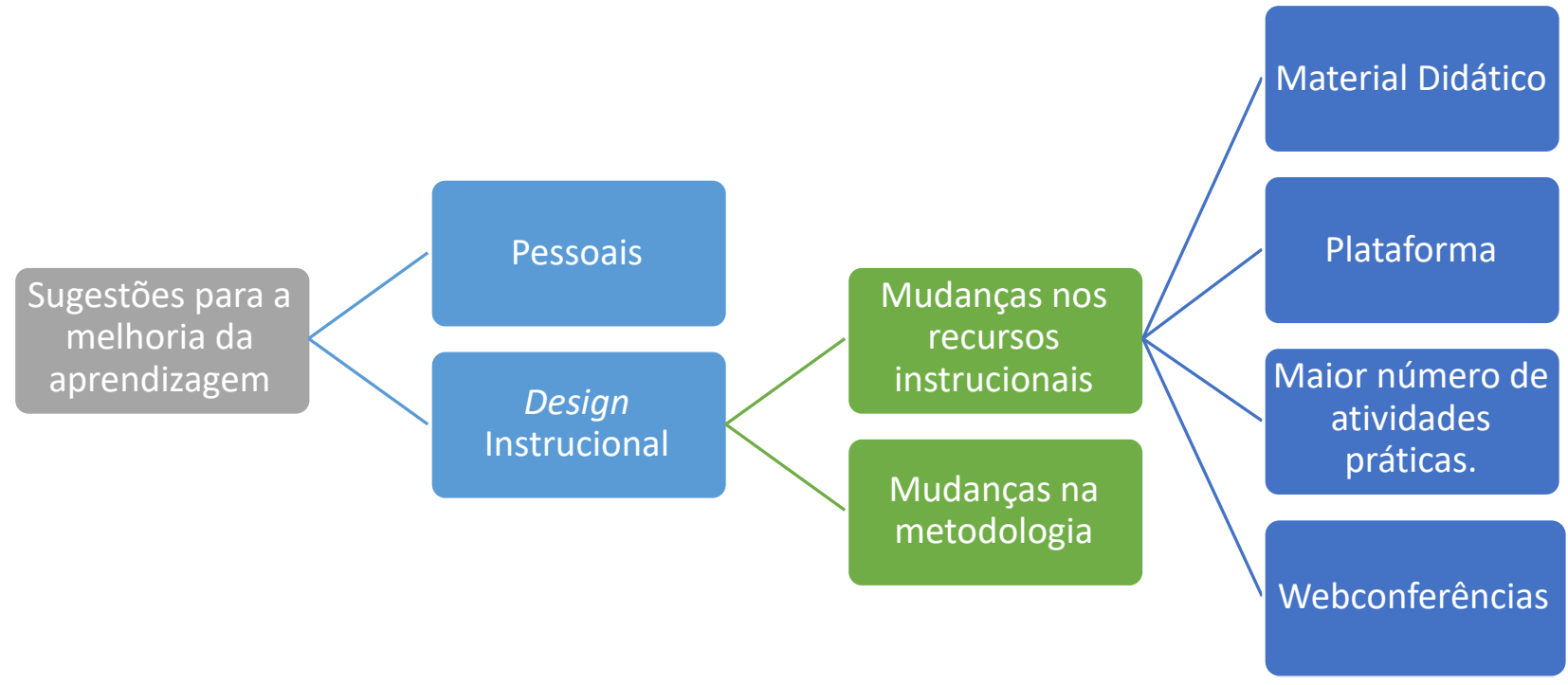

Fonte: dados da pesquisa (2020).

a) Responsabilidades pessoais: refere-se a mudanças na atitude do próprio aluno, por exemplo, organizar melhor o tempo de estudo. Dentre as sugestões para melhorar a aprendizagem nessa categoria destaca-se a seguinte afirmação: "A plataforma do aluno está muito dinâmica e isso é ótimo, os prazos para entrega das atividades também estão bons. Acho que ter um ambiente adequado para estudar, no meu caso, seria o ideal (...)".

b) Mudanças no design instrucional: refere-se a mudanças no modelo instrucional do curso subdivididos em:

b.1) Mudanças nos recursos instrucionais: modificações nos recursos instrucionais disponíveis. De acordo com o recurso instrucional mencionado, divide-se em:

- Mudanças no material didático: material escrito individualizado para cada disciplina com quadros esquemáticos e fluxogramas. Materiais e vídeos disponíveis até a conclusão do curso. Nesta categoria os respondentes sugeriram: "Material teórico disponibilizado em cada matéria"; "Que as aulas iniciais não saíssem da plataforma, pois, às vezes trava e fica difícil voltar. Algumas achei no "YouTube". E por fim, "Esquematizar mais a parte de direito processual.

- Mudanças na plataforma: relativas ao conteúdo e forma de apresentação do conteúdo na plataforma na Web. Dentre as sugestões nessa categoria destaca-se: "Aulas mais animadas para manter acordado, deixar mais chamativo atrativo".

- Maior número de atividades práticas: relativos à contextualização dos conteúdos, exemplos práticos e estudos de casos no material didático. Nesta categoria os alunos fizeram sugestões como:

E1"Mais exercício para fixação do conteúdo, aula de revisão do conteúdo por meio de webconferência com os professores, atividades para cada módulo de cada disciplina, correção de provas e atividades via webconferência (...)".

E2"Mais atividades de aplicação dos conteúdos".

E3 "Maior volume de material em PDF e exemplos práticos como exercício".

E4"(...) Utilização de exemplos são a chave do entendimento da matéria. Podemos decorar um artigo de lei, entretanto, de nada servirá se não sabermos a sua aplicação prática."

E5"Como no Direito os detalhes alteram a interpretação dos fatos, a utilização de exemplos facilita o entendimento e capacita o aluno para elucidar casos complexos. A elaboração de casos hipotéticos colocando em prática a doutrina e a jurisprudência é uma maneira de aprender melhor".

- Webconferência: maior utilização da ferramenta para favorecer a interação entre os alunos e entre os alunos e professores. Com relação a esse assunto os respondentes fizeram algumas sugestões dentre elas: 
E1"Ferramentas como "meet", "zoom" e outras de videoconferência utilizadas após período pandêmico se disponível para uma ou duas aulas seria bem mais produtivo".

E2"Realizações de vídeo conferências com professores e convidados na área (...)".

E3"Continuar com a webconferência, pois será uma forma melhor de tirar as dúvidas com o professor, e com isso teremos um entendimento melhor sobre o assunto".

b.2) Mudanças na metodologia: alterações no modelo instrucional do curso em relação à estrutura do curso e a ausência de aulas presenciais. Nessa categoria os alunos sugeriram:

R1"Possuir ferramenta de comunicação direta com o professor em determinado horário para tirar dúvidas".

Outra sugestão foi:

$R 2$ "Ter uma disciplina no primeiro semestre que nos familiarizasse com a terminologia própria da área jurídica, e, que cada disciplina tivesse um tempo maior para o seu desenvolvimento, pois são muitos vídeos, aulas, sugestões de atividades para serem realizadas e muito pouco tempo para que as mesmas aconteçam."

R3"Aula presencial semanal ou quinzenal".

R4"Tratar o curso de EaD 100\% em formato EaD (sem prova presencial)"

Após a categorização dos dados, percebeu-se que embora a maior dificuldade relatada pelos alunos na questão anterior fosse relacionada a dificuldades de ordem pessoal, a maior parte das sugestões para a melhoria da aprendizagem estão relacionadas a mudanças no design instrucional do curso $(91,3 \%)$, enquanto apenas $8,6 \%$ das assertivas referiram-se a responsabilidades pessoais dos aprendizes (Tabela 20).

Tabela 3. Sugestões para a melhoria da aprendizagem.

\begin{tabular}{lccc}
\hline \multicolumn{1}{c}{ Categoria } & Total de respostas & $\%$ \\
\hline 1-Mudanças no design institucional & 21 & $91,3 \%$ \\
2-Responsabilidades pessoais & Total & 02 & $8,7 \%$ \\
\hline & & 23 & $100 \%$ \\
\hline
\end{tabular}

Fonte: Dados da pesquisa (2020).

Dentre as sugestões para os alunos obterem um melhor aprendizado, 91,3\% atribuíram a mudanças no design instrucional, ou seja, alterações nos recursos utilizados ou na metodologia do curso com a utilização de metodologias ativas. Esses resultados estão em consonância com o estudo de Mill (2018):

Do ponto de vista da formação pela EaD ou pela educação híbrida, essa noção de metodologias ativas pode ser explorada, especialmente porque fomenta a autonomia e a liberdade do educando, que, no caso da EaD, é adulto em processo de formação. Nas discussões de Knowles (1970 e 1986) e de Hase e Kenyon (2001), sobre andragogia e heutagogia (estudo da aprendizagem autodeterminada, o estudante adulto valoriza a aprendizagem autodirigida, a responsabilidade e o controle sobre a própria aprendizado, a definição do que the é mais relevante, a coparticipação nas decisões sobre o que e como aprender etc. Esses princípios podem ser imensamente explorados pelas metodologias ativas nas várias modalidades de educação. (Mill, 2018, pp. 442-443).

Dentre as sugestões de mudanças no design instrucional do curso, percebe-se que os recursos instrucionais foram mencionados com mais frequência (60,86\%). Dentro da categoria dos recursos instrucionais, $14,28 \%$ das assertivas sugeriram mudanças no material didático, seja quanto à melhoria material escrito individualizado para cada disciplina com quadros esquemáticos e fluxogramas além de materiais e vídeos disponíveis até a conclusão do curso. 
Dentre as demais mudanças referentes aos recursos instrucionais, 9,52\% das assertivas sugeriram melhorias no acesso e no conteúdo da plataforma na Web. 28,57\% relataram que estudos práticos e mais exemplos durante as aulas seriam capazes de ajudá-los a aprender melhor e 14,28\% sugeriram melhorias no desenvolvimento de webconferência com os professores, com a finalidade de maior interação (Tabela 4).

Tabela 4. Sugestões de mudanças no design instrucional do curso.

\begin{tabular}{lcc}
\hline \multicolumn{1}{c}{ Categoria } & Total de respostas & $\%$ \\
\hline 1-Mudanças nos recursos instrucionais & & \\
a-Mudanças no material didático & 03 & $14,28 \%$ \\
b-Mudanças na plataforma & 02 & $9,52 \%$ \\
c-Mudanças no número de atividades práticas & 06 & $28,57 \%$ \\
d-Webconferências & 03 & $14,28 \%$ \\
2-Mudanças na metodologia & 07 & $33,33 \%$ \\
\hline \multicolumn{2}{c}{ Total } & 21 \\
\hline
\end{tabular}

Fonte: Dados da pesquisa (2020).

Nos dados coletados, a maioria dos alunos $(28,57 \%)$ sugere que mais atividades práticas e exemplos de aplicação do conteúdo os ajudariam a aprender melhor. Esses resultados conectam-se a um dos princípios da andragogia de Knowles, mencionado no estudo de Munhoz (2017), qual seja, o princípio do propósito, no qual os alunos interessam-se em saber o que aprenderão com esse conteúdo, qual a importância desse aprendizado e para o quê irá servir.

A metodologia do design instrucional direciona suas ações na produção de materiais didáticos instrucionais que potencializem o aprendizado do aluno. Clareza e precisão dos conteúdos a serem passados, contextualização do assunto, significado para a vida prática, estratégias avaliativas eficazes e arquitetura da informação são pontos preconizados durante as ações de design instrucional (Barreto et al., 2007).

Pode-se observar que a maioria dos alunos atribuem a alterações no design instrucional para obterem um melhor aprendizado. Para Mill (2018, p. 163), um design instrucional bem formatado torna possível "o planejamento e o acompanhamento da produção de situações de ensino que possibilitem a melhor aprendizagem dos alunos, de acordo com as suas necessidades e o contexto contemporâneo". Nos cursos EaD o papel do design instrucional é fundamental, pois é uma metodologia de trabalho dedicada aos processos de análise, desenho, desenvolvimento, implementação e avaliação de cursos à distância.

\section{CONCLUSÃO}

Nesse estudo, verificou-se que:

a)o perfil dos participantes, do curso superior de Tecnologia em Serviços Jurídicos pesquisado, é em sua maioria composta por adultos entre 31 e 40 anos, pertencentes ao sexo masculino, casados, que possuem e moram com os filhos e contribuem com mais de $50 \%$ da renda familiar. Houve um equilíbrio de respostas entre os que não possuem graduação e os que possuem graduação anterior;

b) Houve um predomínio de participantes que relataram possuir conhecimentos prévios para a compreensão do conteúdo ministrado no curso e na utilização das ferramentas disponibilizadas no curso;

c)Em relação a utilização do computador todos relataram possuir familiaridade na utilização do equipamento.

d)Em relação ao domínio de recursos utilizados no curso: $20,7 \%$ dos respondentes apresenta algum tipo de dificuldade na utilização do AVA, 10,3\% não possuem domínio do editor de texto 
(word), 6,8\% não possuem domínio do formato PDF, 13,8\% não dominam softwares de execução de vídeo e $23,8 \%$ não dominam as ferramentas de webconferência;

e) Para a solução de dúvidas, verificou-se que entre pedir ajuda ao colega mais experiente, coordenador do curso ou tutor, os respondentes afirmaram que, na maioria das vezes, se reportam ao tutor para sanar eventuais dúvidas ou dificuldades e que participam dos fóruns de discussão. A maioria dos participantes relataram possuir controle sobre a sua aprendizagem e utilizar as orientações do material "guia do aluno" para estudar.

f)Apenas $13,6 \%$ dos respondentes afirmaram que possuem dificuldades com a linguagem jurídica utilizada no curso;

g)A maior dificuldade de aprendizagem apontada pelos alunos está relacionada a dificuldades de cunho pessoal seguida pelas dificuldades relacionadas ao design do curso analisado. Nas dificuldades de ordem pessoal, predominam as dificuldades acadêmicas, seguidas de dificuldades de ordem socioeconômica e estruturais e dificuldades de motivação;

h)Nas dificuldades relacionadas ao design do curso analisado, houve um equilíbrio nas assertivas entre os recursos instrucionais (material didático e plataforma) e a ausência de interação entre colegas, professores e funcionários.

i)Nas sugestões para obtenção de um melhor aprendizado, predominaram as mudanças no design instrucional, ou seja, alterações nos recursos utilizados ou na metodologia do curso. $\mathrm{Na}$ subcategoria recursos instrucionais houve um predomínio de sugestões em relação as alterações no material didático. Foram sugeridas alterações na plataforma, alteração no número de atividades práticas e aumento no número de webconferências. Na subcategoria metodologia do curso, as sugestões se referiram a alterações no modelo instrucional do curso em relação à estrutura do curso e à ausência de aulas presenciais.

Verifica-se que é fundamental que o aluno que se matricule em um curso a distância esteja ciente das competências necessárias para o investimento nessa modalidade, bem como o papel que deverá ser capaz de exercer durante esse processo. A capacidade de exercer um papel ativo e crítico perante o próprio processo de aprendizagem, além da capacidade de gerenciamento do tempo e das tarefas de aprendizagem, contribuem para uma aprendizagem autônoma e bem-sucedida.

As sugestões dos participantes, nessa pesquisa, que solicitaram, dentre outras práticas pedagógicas: mais atividades práticas, exemplos contextualizados, aplicabilidade dos conteúdos, maior interação, evidenciam a necessidade da articulação dos projetos pedagógicos aos processos educacionais de aprendizagem no contexto de cursos ofertados à distância com a permanente 'escuta' de todos os envolvidos.

Contribuições dos Autores: Vieira, P. S.: concepção e desenho, aquisição de dados, análise e interpretação dos dados, redação do artigo, revisão crítica relevante do conteúdo intelectual; Mazzafera, B. L.: concepção e desenho, redação do artigo, revisão crítica relevante do conteúdo intelectual. Todos os autores leram e aprovaram a versão final do manuscrito.

Aprovação Ética: Aprovado pelo Comitê de Ética em Pesquisa em Seres Humanos da Universidade Pitágoras Unopar. CAAE: 30054120.7.0000.0108.

Agradecimentos: Não aplicável.

\section{REFERÊNCIAS}

Aquino, J. A. T. \& Mazzafera B. L. (2018). O domínio de tecnologias digitais na percepção de alunos do curso de ciências contábeis da Universidade Estadual de Londrina. Laplage em revista, (4)3, pp.168-179.

https://dialnet.unirioja.es/servlet/articulo?codigo=6788960

Andrade, A, de F.B. (2009). Cursos Superiores de Tecnologia: um estudo de sua demanda sob a ótica dos estudantes. Dissertação (Mestrado em Educação). Brasília: Universidade de Brasília,

https://repositorio.unb.br/bitstream/10482/4126/1/2009 AndreadeFariaBarrosAndrade.pdf?or. 
Barreto, C. C. (Org.); Rodrigues, S.; Carvalho, R. P.; Rabelo, C. O.; Fialho, A. P. A.; Meyohas, J. (2007). Planejamento e elaboração de material didático impresso para educação a distância. Rio de Janeiro: Fundação Cecierj.

https://canal.cecierj.edu.br/recurso/9653

Belloni, M. L. (2012). Educação a distância. 6. ed. Campinas: Autores Associados.

Brasil. Ministério de Educação e Cultura. LDB - Lei no 9394/96, de 20 de dezembro de 1996. Estabelece as diretrizes e bases da Educação Nacional. Brasília: MEC, 1996.

Brasil. Decreto 5.622, de 19 de dezembro de 2005. Regulamenta o artigo 80 da Lei no 9.394, de 20 de dezembro de 1996, que estabelece as diretrizes e bases da educação nacional. Diário Oficial da União: Brasília, D.F, 20 dez. 2005.

Brasil. Decreto n. 9.057, de 25 de maio de 2017. Regulamenta o art. 80 da lei n. 9.394/1996 e revoga o decreto $n$. 5.622/2005 e o art. $1^{\circ}$ do decreto n. 6.303/2007. Diário oficial da união: seção 1, Brasília, D.F, p. 3, 25 de maio. 2017.

Brasil. Ministério da Educação. Instituto Nacional de estudos e pesquisas educacionais Anísio Teixeira. Censo da Educação Superior: Sinopse Estatística, 2019. http://portal.inep.gov.br/web/guest/microdados

Brasil. Ministério da Educação. Portaria no 413, de 11 de maio de 2016. Aprova, em extrato, o Catálogo Nacional de Cursos Superiores de Tecnologia. Diário Oficial da União. Seção 1, Brasília, DF, p. 48, 12 mai. de 2016.

https://www.in.gov.br/materia/-/asset publisher/Kujrw0TZC2Mb/content/id/21520646/do1-2016-05-12-portaria-n413-de-11-de-maio-de-2016-21520595

Burian, E. A. O. (2009). Dificuldade de estudar on-line: uma narrativa de experiência de aprendizagem. 2009.

Dissertação (Mestrado em Lingüística). São Paulo: Pontifícia Universidade Católica de São Paulo.

https://tede2.pucsp.br/handle/handle/14106

Castro, N. J. et al. (2001). O estudo a distância com apoio da Internet. In: Congresso Internacional de Educação a Distância. Brasília.

http://www.abed.org.br/site/pt/midiateca/textos ead/683/2005/11/o estudo a distancia com apoio da internet

Censo ead.BR. (2018). Relatório analítico da aprendizagem a distância no Brasil 2018 = Censo EAD.BR: analytic report of distance learning In: Brazil 2018 [livro eletrônico]/[organização]

ABED - Associação Brasileira de Educação a Distância. Camila Rosa (tradutora). Curitiba: InterSaberes, 2019. http://abed.org.br/arquivos/CENSO DIGITAL EAD 2018 PORTUGUES.pdf

Fernandes, J. G. (2017). Autorregulação da aprendizagem de alunos matriculados no curso de Pedagogia ofertado a distância. Dissertação (Mestrado em Ensino). Londrina: Universidade Norte do Paraná.

https://docplayer.com.br/59944688-Autorregulacao-da-aprendizagem-de-alunos-matriculados-no-curso-depedagogia-ofertado-a-distancia.html

Godoi, M. A.; Oliveira, Sandra M. S. S. (2016). O perfil do aluno da educação a distância e seu estilo de aprendizagem. EaD em Foco, (6)2, pp. 76-91. https://eademfoco.cecierj.edu.br/index.php/Revista/article/view/383/177

Jonaitis, S. (2005). A Guide for the Distance Education Learner. In: Levine, S. J. (ed.) Making distance education work: understanding learning and learners at a distance. Learner Associates.net, pp. 123-130.

http://learnerassociates.net/learners/chap12.pdf

Jucá, M. C.; Oliveira, P. J. de; Souza, R. J. de. (2010). Cursos superiores tecnológicos: um avanço da educação superior no brasil. In: X Colóquio Internacional sobre Gestión Universitaria em América del sur, Mar del Plata.

https://repositorio.ufsc.br/bitstream/handle/123456789/97065/CURSOS\%20SUPERIORES\%20TECNOL\%D3GICOS\%20 UM\%20AVAN\%C7O\%20DA\%20EDUCA\%C7\%C3O\%20SUPERIO.pdf?sequence=1\#: :text=No\%20final\%20da\%20d\%C3\% A9cada $\% 20$ de,grau $\% 20$ m $\%$ C3\%A9dio\%20e\%200\%20superior $\% 2 C$

Keegan, D. (1996) Foundations of distance education. 3. ed. Londres: Routledge

Lott, A. C. de O.; Freitas, A. S. de; Ferreira, J. B.; Lott, Y.M. (2018). Persistência e Evasão na Educação a Distância: Examinando Fatores Explicativos. Revista Eletrônica de Ciência Administrativa, (17) 2, pp. 149-171.

http://www.spell.org.br/documentos/ver/49592/persistencia-e-evasao-na-educacao-a-distancia--examinandofatores-explicativos-/i/pt-br

Mill, Daniel. (2018). Dicionário Crítico de Educação e Tecnologias e de Educação a Distância. Campinas: Papirus.

Moore, M. G. Independent Study.(1980) In: Boyd, R.; Apps, J. (eds.) Redefining the discipline of adult education. San Francisco: Jossey-Bass, pp. 16-31 http://www.ed.psu.edu/acsde/pdf/independent study.pdf

Moore, M. G. \& Kearsley, G. (2008). Educação a distância: Uma visão integrada. São Paulo: Cengage Learning. https://www.academia.edu/5116276/Uma Vis\%C3\%A3o Integrada 
Mota, J. G. \& Silvane \& L, E. (2014). Reflexão sobre o perfil do aluno como determinante para a motivação e aprendizagem em curso de ead. Cadernos de Educação, Tecnologia e Sociedade, (7) pp. 355-363, 2014. https://www.locus.ufv.br/bitstream/123456789/18186/1/artigo.pdf

Munhoz, A S. (2017). Angragogia: a educação de jovens e de adultos em ambientes virtuais. Curitiba: InterSaberes.

Munhoz, C. M. E. (2018). Autorregulação: aprendendo a aprender por meio de estratégias de aprendizagem. Dissertação (Mestrado em Ensino). Londrina: Universidade Norte do Paraná, https://repositorio.pgsskroton.com/bitstream/123456789/17339/1/Carla\%20Munhoz\%20-\%20UNOPAR\%20\%20Dissertacao\%20BIBLIOTECA\%2007.4.2018.pdf

Nascimento, J. F. S. do. (2013). Análise das dificuldades de aprendizagem numa disciplina de química orgânica do curso de química na modalidade à distância da UFRN. Dissertação (Mestrado em Físico-Química). Natal: Universidade Federal do Rio Grande do Norte, 2013.

https://repositorio.ufrn.br/jspui/bitstream/123456789/17714/1/JarleyFSN_DISSERT.pdf.

Rabello, C. R. L. (2007). Aprendizagem na educação à distância: dificuldades dos discentes de licenciatura em ciências biológicas na modalidade semipresencial. Dissertação (Mestrado em Educação). Rio de Janeiro: Universidade Federal do Rio de Janeiro. https://docplayer.com.br/62597240-Aprendizagem-na-educacao-a-distancia-dificuldades-dosdiscentes-de-licenciatura-em-ciencias-biologicas-na-modalidade-semipresencial.html.

Reis, M. G. dos. (2013). Viabilidades e dificuldades do ensino de ecologia oferecido na modalidade EaD - uma análise da percepção docente. Dissertação (Mestrado em Ensino). São Paulo: Universidade de São Paulo Universidade de São Paulo. https://teses.usp.br/teses/disponiveis/81/81133/tde-19012015-143800/pt-br.php

Rodrigues, N. (2013). Avaliação da Aprendizagem em Educação a Distância através do Fórum (Interface Educacional). Interfaces Científicas, (1)3, pp. 43-53. https://doi.org/10.17564/2316-3828.2013v1n3p43-53

Rosetti, J. S. (2011). Histórico e contexto econômico dos cursos superiores de tecnologia no Brasil. Observatorio de la Economía Latinoamericana, (152) https://www.eumed.net/cursecon/ecolat/br/11/rjs.htm

Schwartzman, S. \& Christophe, M. (2005). A sociedade do conhecimento e a educação tecnológica. SENAI, Brasília. https://ufrb.edu.br/educacaodocampocfp/images/2005 senai.pdf

Schnitman, I. M. (2010). O perfil do aluno virtual e as teorias de estilos de Aprendizagem. In: 3o Simpósio Hipertexto e Tecnologias na Educação. Redes Sociais e Aprendizagem, Recife. http://nehte.com.br/simposio/anais/AnaisHipertexto-2010/Ivana-Maria-Schnitman.pdf

Silva, E.S. (2017). A integração das tecnologias à licenciatura em Matemática: Percepções do professor sobre dificuldades e desafios para a formação inicial. Dissertação (Mestrado em Ensino). Campina Grande: Universidade Estadual da Paraíba. http://tede.bc.uepb.edu.br/ispui/handle/tede/2768

Silva, A. L. da \& SÁ, I. de. (1997). Saber estudar e estudar para saber. 2. ed. Portugal: Porto Editora.

Silveira, M. L. da. (2013). Dificuldades de aprendizagem e concepções alternativas em biologia: a visão de professores em formação sobre o conteúdo de citologia. Dissertação (Mestrado em Ensino de Ciências Naturais e Matemática). Natal: Universidade Federal do Rio Grande do Norte. https://repositorio.ufrn.br/jspui/handle/123456789/16104.

Suguimoto, H. H. et al. (2017). Avaliação do letramento digital de alunos ingressantes do ensino superior: uma abordagem exploratória do conhecimento computacional, comunicacional e informacional. Rev. Bras. Estud. Pedagog, Brasília, (98) 250, pp. 805-822, https://doi.org/10.24109/2176-6681.rbep.98i250.3011

Umekawa, E. E. R. (2014). Preditores de fatores relacionados à evasão e a persistência discente em ações educacionais a distância. Dissertação (Mestrado em Psicologia), Ribeirão Preto: Universidade de São Paulo.

https://www.teses.usp.br/teses/disponiveis/59/59137/tde-23032014-115420/pt-br.php

Recebido: 9 de julho de 2021 | Aceito: 23 de setembro de 2021 | Publicado: 1 de novembro de 2021 